Nippon Suisan Gakkaishi $\quad 59(1), 171-176(1993)$

\title{
Efficacy of Dehydro-L-Ascorbic Acid as a Dietary Vitamin C Source in Rainbow Trout
}

\author{
Mamoru Sato, ${ }^{* 1}$ Tomoaki Mitani, ${ }^{11}$ Taiko Miyasaki, *1 \\ Reiji Yoshinaka, ${ }^{2}$ and Morihiko Sakaguchi*1 \\ (Received August 25, 1992)
}

\begin{abstract}
Dehydro-L-ascorbic acid (DAsA), an oxidized form of L-ascorbic acid (AsA), was tested for efficacy as a vitamin $C$ source and safety in young rainbow trout Onchorhynchus mykiss. The fish, weighing about $100 \mathrm{~g}$ on average, were fed with experimental diets containing various levels of DAsA or AsA for 6 weeks. The fish receiving the AsA-deficient diet had very low concentrations of AsA in several tissues and plasma. In the fish fed with the DAsA-supplemented diet, similar to those fed with the AsA-supplemented diet, only the AsA level rose markedly, whereas DAsA did not increase. There were no statistical differences in the AsA and DAsA concentrations in the various tissues and plasma between AsA- and DAsA-supplemented groups. The glutathione levels of tissues and hematological parameters did not vary between the AsA- and DAsA-supplemented groups. In addition, no cell disruption was brought about by DAsA administration.

These resuits suggest that dietary DAsA is readily reduced to AsA in the fish body and can be effectively utilized by the rainbow trout as a vitamin $C$ source.
\end{abstract}

L-Ascorbic acid (AsA) is readily oxidized to dehydro-L-ascorbic acid (DAsA) during processing and storage of feeds because of its instability. It is possible that cultured fish are fed with diets containing considerable amounts of DAsA.

The vitamin $C$ action of AsA in animals is based on the oxidation process of AsA to DAsA via mono-DAsA, while DAsA itself has no vitamin $\mathrm{C}$ activity. ${ }^{1}$ DAsA is known to be reversibly converted to AsA in animal tissues. Various studies have so far been undertaken to evaluate the antiscorbutic activity of DAsA in guinea pigs $^{2,3)}$ and humans. ${ }^{4-8)}$ Tsujimura et al. ${ }^{5)}$ concluded that DAsA had the antiscorbutic activity equivalent to AsA, on the basis of the results of urinary AsA excretions of healthy men who were fed diets supplemented with DAsA. Otsuka et al. ${ }^{7)}$ showed that the antiscorbutic activity of DAsA in vitamin C-deficient guinea pigs was less than that of AsA. There are few reports on vitamin $C$ activity of DAsA in fishes.

The present study was designed to clarify the conversion of dietary DAsA to AsA in the fish body and to evaluate the efficacy of DAsA as a vitamin $\mathrm{C}$ source for rainbow trout.

\section{Materials and Methods}

\section{Reagents}

AsA was obtained from Nacalai Tesque Inc. (Kyoto). DAsA was prepared by the method of Tsujimura. ${ }^{\text {s> }}$

\section{Fish, Diets, and Feeding Methods}

Young rainbow trout Onchorhynchus mykiss, weighing about $100 \mathrm{~g}$ on average, were used. The fish were divided into 5 groups of 10 individuals each, and each group was kept in an aquarium (50 $l$ ) supplied with well water at $16^{\circ} \mathrm{C}$. The basal diet (AsA-free) was the same as that reported previously. ${ }^{0)}$ The experimental diets were prepared from the AsA-free basal diet supplemented with either 50 or $1,000 \mathrm{mg}$ of AsA or equimolar amounts of DAsA (49 and $989 \mathrm{mg}$, respectively) per $100 \mathrm{~g}$ of dry basal diet. These diets are referred to as A-50, A-1000, and D-50, D-1000, respectively. As a control, an AsAfree basal diet is referred to as $F$. Each diet powder $(100 \mathrm{~g})$ was mixed well with $60 \mathrm{ml}$ of water and made into pellets at room temperature. Each pelleted moist diet was sealed in a plastic bottle and stored at $-80^{\circ} \mathrm{C}$ until use. These

*1 Department of Fisheries, Faculty of Agriculture, Kyoto University, Kitashirakawa, Sakyo, Kyoto 606-

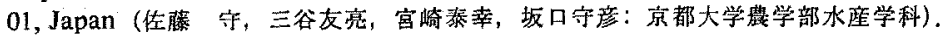

*2 Department of Marine Bioscience, Faculty of Biotechnology, Fukui Prefectural University, Matsuoka,

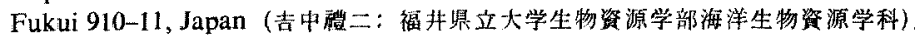


Table 1. Stability of AsA and DAsA during pelleting and storage of the experimental diets

\begin{tabular}{|c|c|c|c|c|c|c|c|c|}
\hline \multirow{2}{*}{ Diet } & & \multirow{2}{*}{$\begin{array}{c}\text { Storage } \\
-80^{\circ} \mathrm{C} \\
\text { (day) }\end{array}$} & \multirow{2}{*}{$\begin{array}{l}\text { Moisture } \\
(\%)\end{array}$} & \multirow{2}{*}{$\begin{array}{l}\text { Total AsA*1 } \\
(\mu \mathrm{g} / \mathrm{g} \text { of dry })\end{array}$} & \multirow{2}{*}{$\begin{array}{l}\text { Yield } \\
(\%)\end{array}$} & \multicolumn{3}{|c|}{ Composition (\%) } \\
\hline & & & & & & AsA & DAsA & DKG \\
\hline \multirow[t]{4}{*}{ A-50 } & $\begin{array}{l}\text { Pre-pelleted } \\
\text { diet powder }\end{array}$ & 0 & 9.3 & $551.3 \pm 2.8^{* 2}$ & 100 & 100 & 0 & 0 \\
\hline & Pellets & 0 & 41.6 & $515.8 \pm 9.6$ & 93.6 & $71.6 \pm 2.3$ & $27.6 \pm 4.4$ & $0.8 \pm 0.4$ \\
\hline & $\prime \prime$ & 5 & 41.5 & $516.4 \pm 8.8$ & 93.7 & $71.3 \pm 3.6$ & $27.8 \pm 3.5$ & $0.9 \pm 0.3$ \\
\hline & $"$ & 10 & 41.6 & $515.5 \pm 4.9$ & 93.5 & $71.5 \pm 3.2$ & $26.3 \pm 3.0$ & $2.2 \pm 0.3$ \\
\hline \multirow[t]{4}{*}{ D.50 } & $\begin{array}{l}\text { Pre-pelleted } \\
\text { diet powder }\end{array}$ & 0 & 9.2 & $540.2 \pm 4.2$ & 100 & 0 & 100 & 0 \\
\hline & Pellets & 0 & 41.6 & $494.4 \pm 18.6$ & 91.5 & 0 & $97.8 \pm 0.8$ & $2.2 \pm 0.8$ \\
\hline & $" \prime$ & 5 & 41.6 & $486.6 \pm 26.3$ & 90.1 & 0 & $97.9 \pm 0.9$ & $2.1 \pm 0.9$ \\
\hline & " & 10 & 41.3 & $482.3 \pm 26.0$ & 89.3 & 0 & $92.0 \pm 1.6$ & $8.0 \pm 1.6$ \\
\hline
\end{tabular}

*1 Total AsA (AsA+DAsA +DKG) was determined by the hydrazine method.10) DKG content was determined by the hydrazine method after the reduction of DAsA with dithithreitol to AsA.

*2. Mean \pm S.D. $(\mathrm{n}=3)$.

diets were prepared every 10 days. As shown in Table 1, when AsA was added to the diet at a level of $50 \mathrm{mg}$ per $100 \mathrm{~g}$ of diet, about $6 \%$ of the added AsA was lost during diet preparation and about $28 \%$ of the remaining total AsA was oxidized to DAsA. Only a small amount of diketo-L-gulonic acid (DKG) was detected in the pellets. When DAsA was added to the diet at a level of $49 \mathrm{mg}$ ( $50 \mathrm{mg}$ AsA eq.) per $100 \mathrm{~g}$ of the diet, about $8 \%$ of the added DAsA was lost during diet preparation. After storage at $-80^{\circ} \mathrm{C}$ for 10 days, AsA, DAsA, and DKG in diet A-50, as well as DAsA and DKG in diet D-50 remained unchanged.

Before initiation of the experiment, each group of fish was given the AsA-free diet for 2 weeks. Then each group was fed their prescribed experimental diet twice a day at a level of $2 \%$ of body weight. After 3 and 6 weeks of feeding, 3-5 fish were sampled randomly from each group to analyze AsA, DAsA, glutathione (GSH), and hematological parameters.

\section{Determination of AsA, DAsA, and GSH}

AsA, DAsA, and GSH were determined by high-performance liquid chromatography (HPLC) using a reversed-phase column (COSMOSIL $5 \mathrm{C}_{18}, 4.6 \times 150 \mathrm{~mm}$, Nacalai Tesque) and an electrochemical detector (model L-ECD-6A, Shimadzu). The detector was set at $+800 \mathrm{mV}$ vs. $\mathrm{Ag} / \mathrm{AgCl}$. The mobile phase was $20 \mathrm{~mm}$ $\mathrm{NaH}_{2} \mathrm{PO}_{4}$ containing $1 \mathrm{~mm}$ EDTA, $3 \mathrm{~mm}$ sodium 1-octanesulfonate, and $0.015 \%(w / v)$ metaphosphoric acid, the $\mathrm{pH}$ of which was adjusted to 3.00 with $\mathrm{H}_{3} \mathrm{PO}_{4}$, The flow rate was $0.8 \mathrm{~m} / / \mathrm{min}$.
The column and detector were kept at $40^{\circ} \mathrm{C}$.

The preparation of tissue samples to determine AsA and GSH was carried out as described previously. ${ }^{11}$ For the determination of blood GSH, each blood sample $(500 \mu l)$ was mixed well with $100 \mu l$ of $6 \%$ acetic acid, and then mixed with $400 \mu \mathrm{l}$ of cold $5 \%$ metaphosphoric acid, and filtered through a $0,45 \mu \mathrm{m}$ syringe filter. The filtrate was injected into the HPLC system.

DAsA was reduced with dithiothreitol to AsA. Each sample solution $(900 \mu l)$ was mixed with $2 \%$ dithiotheritol $(100 \mu l)$ and neutralized with $5 \mathrm{~N} \mathrm{NaOH}$. The mixture was allowed to stand for $10 \mathrm{~min}$ under cooling in an ice bath, and filtered through a $0.45 \mu \mathrm{m}$ syringe filter. Total AsA (AsA +DAsA) of the filtrate was analyzed by HPLC. DAsA content was determined by subtracting the AsA value from total AsA value.

\section{Determination of Blood Glucose and Activities of GPT and GOT in Serum}

Blood was collected into test tubes by cutting the caudal peduncle and kept at room temperature for $1 \mathrm{~h}$. The blood was centrifuged at $700 \times \mathrm{g}$ for $10 \mathrm{~min}$ to obtain serum, which was then kept at $0^{\circ} \mathrm{C}$ and analyzed within 4 to $5 \mathrm{~h}$. Blood glucose and activities of GPT and GOT in serum were estimated by a Rapid Blood Analyzer (RaBA-3010, Chugai).

\section{Statistical Analysis}

The data were analyzed statistically by Student's $t$ test. 


\section{Results}

The AsA and DAsA concentrations in the plasma are presented in Table 2. The fish in group $F$ had a very low AsA concentration. The plasma AsA concentration of group D-50 was not significantly different from that of group A-50. The plasma AsA concentrations of groups D-1000 and A-1000 were very high after 3 weeks of feeding. The AsA concentrations of groups D-1000 and A-1000 were significantly higher $(P<0.05)$ than those of groups D-50 and A-50. However, no significant difference was observed between group D-1000 and group A-1000. The DAsA concentrations in the plasma were below detectable limits even in the DAsA $1000 \mathrm{mg}$ supplemented group, except for group F.

Table 3 shows the concentrations of AsA and

Table 2. Concentration of AsA and DAsA in plasma of rainbow trout fed varying levels of DAsA and AsA for 3 and 6 weeks

\begin{tabular}{|c|c|c|c|c|}
\hline \multirow{2}{*}{ Group } & \multicolumn{2}{|c|}{ After 3 weeks } & \multicolumn{2}{|c|}{ After 6 weeks } \\
\hline & AsA & DAsA & AsA & DAsA \\
\hline$F$ & $30.1 \pm 10.2^{* 1}$ & $0.6 \pm 0.5$ & $31.2 \pm 8.0$ & $7.5 \pm 1.1$ \\
\hline A-50 & $167.6 \pm 35.2$ & n.d.*2 & $218.7 \pm 38.1$ & n.d. \\
\hline D. 50 & $176.7 \pm 76.7$ & n.d. & $181.8 \pm 77.8$ & n.d. \\
\hline A-1000 & $897.2 \pm 84.7$ & n.d. & $430.7 \pm 120.5$ & n.d. \\
\hline D-1000 & $933.5 \pm 109.7$ & n.d. & $562.5 \pm 164.2$ & n.d. \\
\hline
\end{tabular}

Table 3. Concentration of AsA and DAsA in tissues of rainbow trout fed varying levels of DAsA or AsA for 3 and 6 weeks

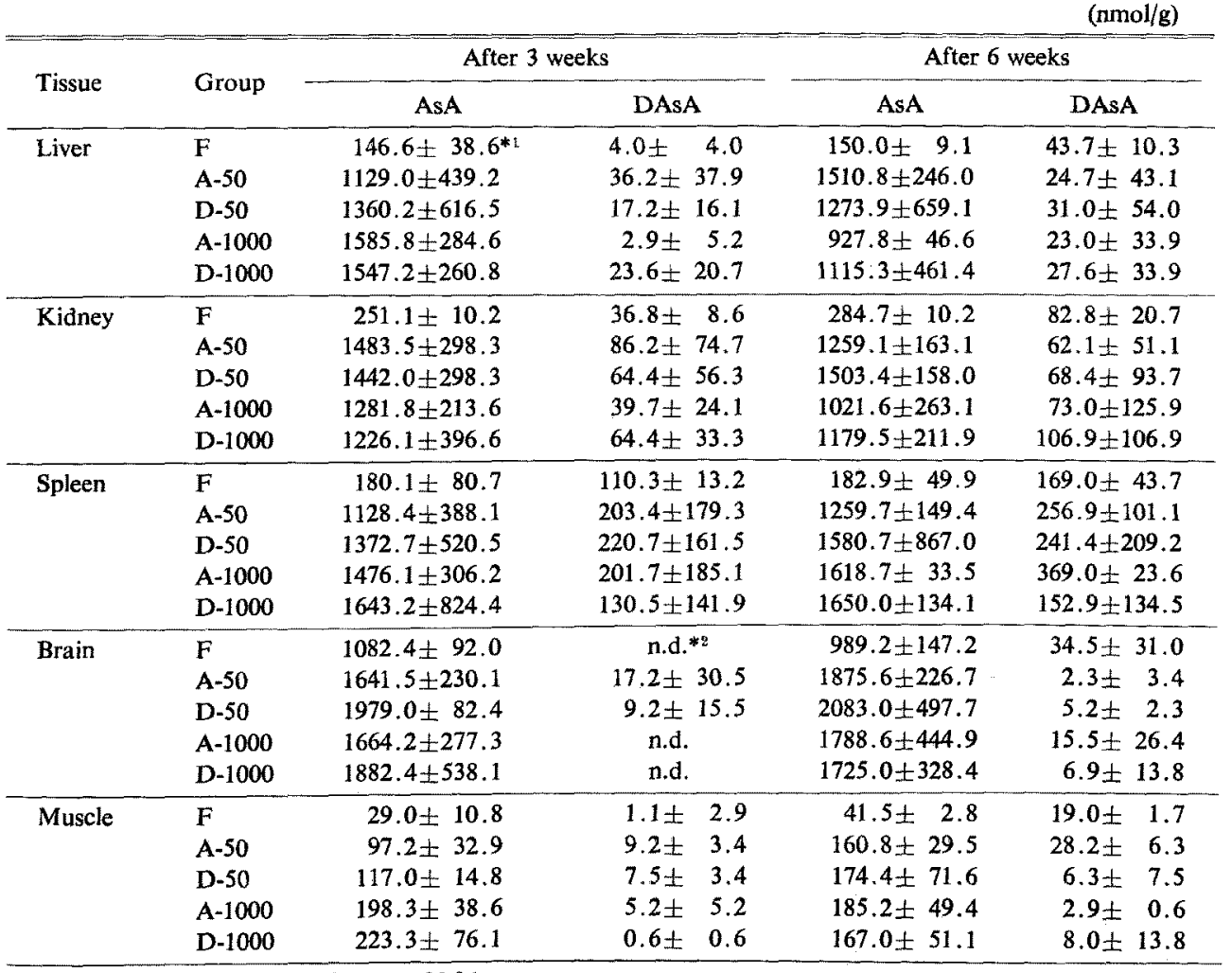

*1 Mean + S.D. Each value is the mean of 3 fish.

*2 D.d.; not detected (below $0.2 \mathrm{nmol} / \mathrm{g}$ ). 
DAsA in the liver, kidney, spleen, brain, and muscle of rainbow trout fed with the experimental diets for 3 and 6 weeks. The concentrations of AsA in the tissues of the groups fed with the DAsA-supplemented diet were significantly higher than those of group F. However, no significant difference was observed between AsA-supplemented and DAsA-supplemented groups for the liver, kidney, spleen, brain, and muscle AsA concentrations after 3 and 6 weeks of feeding. In all of the groups, DAsA concentrations of the spleen and kidney were high compared with those of the liver, brain, and muscle. But no significant difference in the tissue DAsA concentrations was observed between DAsA-supplemented and AsA-supplemented groups. Moreover, within each tissue no significant difference in the DAsA concentration was observed among the groups fed with diet F, A-50, D-50, A-1000, and D-1000 for 3 and 6 weeks. These results suggest that dietary DAsA was readily reduced in the fish body and utilized as AsA by rainbow trout.

Table 4 shows the GSH concentrations in the liver, kidney, spleen, brain, muscle, and blood of rainbow trout fed with the experimental diets for 3 and 6 weeks. The GSH concentrations of none of the tissues examined except liver and blood in groups A-50 and D-50 after 3 weeks of feeding were significantly different from those of group F. The GSH concentrations of all the tissues except muscle and blood in groups A-1000 and D-1000 were significantly lower $(P<0.05)$ than those of group $F$. The GSH concentrations of the tissues and blood in group $F$ remained almost constant until 6 weeks of feeding. The GSH concentrations of groups fed with the diets supplemented with AsA or DAsA (groups A-50, D-50, A-1000, and D-1000) were significantly lower $(\boldsymbol{P}<0.05)$ than those of the AsA-deficient group. No significant differences in GSH concentrations were observed in any of the tissues examined among groups A-50, D-50, A-1000, and D-1000 after 6 weeks of feeding.

Table 5 shows the hematocrit values, blood glucose levels, and serum GPT and GOT activities of rainbow trout fed with the experimental diets for 6 weeks. In groups F, blood glucose level was slightly higher than those of the AsAsupplemented and DAsA-supplemented groups, although the level was not significantly different.

Table 4. Concentration of GSH in blood and tissues of rainbow trout fed varying levels of DAsA or AsA for 3 and 6 weeks

\begin{tabular}{clcccccc}
\hline $\begin{array}{c}\text { Feeding } \\
\text { period }\end{array}$ & Group & $\begin{array}{c}\text { Blood } \\
(\mathrm{nmol} / \mathrm{m} l)\end{array}$ & $\begin{array}{c}\text { Liver } \\
(\mathrm{nmol} / \mathrm{g})\end{array}$ & $\begin{array}{c}\text { Kidney } \\
(\mathrm{nmol} / \mathrm{g})\end{array}$ & $\begin{array}{c}\text { Spleen } \\
(\mathrm{nmol} / \mathrm{g})\end{array}$ & $\begin{array}{c}\text { Brain } \\
(\mathrm{nmol} / \mathrm{g})\end{array}$ & $\begin{array}{c}\text { Muscle } \\
(\mathrm{nmol} / \mathrm{g})\end{array}$ \\
\hline 3 weeks & F & $1240 \pm 100^{*}$ & $2900 \pm 250$ & $2800 \pm 460$ & $3680 \pm 460$ & $1500 \pm 40$ & $390 \pm 30$ \\
& A-50 & $1170 \pm 80$ & $3380 \pm 160$ & $3280 \pm 610$ & $3810 \pm 420$ & $1510 \pm 10$ & $430 \pm 100$ \\
& D-50 & $1160 \pm 120$ & $3670 \pm 160$ & $2910 \pm 150$ & $3720 \pm 90$ & $1160 \pm 390$ & $350 \pm 40$ \\
& A-1000 & $540 \pm 70$ & $1450 \pm 420$ & $1370 \pm 110$ & $1830 \pm 650$ & $610 \pm 20$ & $270 \pm 70$ \\
& D-1000 & $570 \pm 150$ & $1150 \pm 60$ & $1610 \pm 460$ & $2220 \pm 160$ & $740 \pm 60$ & $270 \pm 60$ \\
\hline 6 weeks & F & $1130 \pm 230$ & $2140 \pm 240$ & $2590 \pm 300$ & $3210 \pm 710$ & $1150 \pm 410$ & $320 \pm 70$ \\
& A-50 & $690 \pm 110$ & $1200 \pm 270$ & $1330 \pm 220$ & $1630 \pm 280$ & $570 \pm 100$ & $290 \pm 210$ \\
& D-50 & $820 \pm 70$ & $1090 \pm 440$ & $1640 \pm 80$ & $2310 \pm 230$ & $630 \pm 190$ & $230 \pm 40$ \\
& A-1000 & $590 \pm 240$ & $1270 \pm 140$ & $1370 \pm 20$ & $1590 \pm 110$ & $650 \pm 100$ & $310 \pm 80$ \\
& D-1000 & $590 \pm 80$ & $1440 \pm 370$ & $1240 \pm 420$ & $1290 \pm 730$ & $610 \pm 190$ & $230 \pm 50$ \\
\hline
\end{tabular}

* Mean IS.D. Each value is the mean of 3 fish.

Table 5. Hematocrit values, blood glucose levels and serum GPT and GOT activities of rainbow trout fed varying levels of DAsA or AsA for 6 weeks

\begin{tabular}{lcccc} 
Group & $\begin{array}{c}\text { Hematocrit value } \\
(\%)\end{array}$ & $\begin{array}{c}\text { Blood glucose } \\
(\mathrm{mg} / 100 \mathrm{~m} l)\end{array}$ & $\begin{array}{c}\text { GPT } \\
\text { (karmen unit) }\end{array}$ & $\begin{array}{c}\text { GOT } \\
\text { (karmen unit) }\end{array}$ \\
\hline F & $37.6 \pm 3.8^{*}$ & $80.6 \pm 5.3$ & $20.3 \pm 1.5$ & $475.0 \pm 70.5$ \\
A-50 & $36.4 \pm 3.4$ & $72.6 \pm 8.7$ & $17.5 \pm 4.8$ & $413.3 \pm 102.5$ \\
D-50 & $36.7 \pm 5.1$ & $68.8 \pm 18.8$ & $31.0 \pm 7.1$ & $530.0 \pm 74.7$ \\
A-1000 & $37.9 \pm 5.2$ & $65.0 \pm 9.1$ & $19.0 \pm 3.5$ & $475.0 \pm 184.3$ \\
D-1000 & $38.1 \pm 3.9$ & $63.6 \pm 9.8$ & $33.5 \pm 8.4$ & $463.3 \pm 46.5$ \\
\hline
\end{tabular}

* Mean \pm S.D. Each value is the mean of 5 fish. 
Also, no significant difference in the hematocrit values was observed between AsA-supplemented and DAsA-supplemented groups. The activities of GPT and GOT in serum were slightly higher in the DAsA-supplemented groups than those in the AsA-supplemented groups, but the difference was not significant $(P>0.05)$.

\section{Discussion}

The present study indicated that there were no significant differences in AsA concentrations in the tissues and plasma between groups supplemented with DAsA and those with equimolar amounts of AsA. This result suggests that orally administered DAsA is readily reduced to AsA in the fish body and could be effectively utilized by the rainbow trout as a vitamin $C$ source.

DAsA has been shown to prevent scurvy in guinea pigs ${ }^{2,3}$ and humans..$^{4-8}$ Torbert ${ }^{12}$ suggested that the vitamin $\mathrm{C}$ activity of DAsA is about $70 \%$ of the AsA in guinea pigs. Tsujimura et al. ${ }^{5)}$ concluded that DAsA had the antiscorbutic activity equivalent to AsA on the basis of results of urinary AsA excretions of healthy men who were fed diets supplemented with DAsA. Otsuka et al. ${ }^{7)}$ showed that the antiscorbutic effect of DAsA in guinea pigs was less than that of AsA administered intravenously. It is apparent from the present study that the antiscorbutic activity of DAsA is equivalent to AsA in rainbow trout under these experimental conditions.

Patterson ${ }^{13)}$ observed that injection of large doses of DAsA intravenously in rats caused temporary diabetes mellitus, and large doses of repeated injections caused permanent atrophy of the $\beta$-cells of the islets of Langerhans. Chatterjee et al. ${ }^{14}$ also reported that as the blood DAsA levels increased in guinea pigs fed with high doses of AsA, there was a concomitant increase in blood sugar levels. In the present study, after feeding large doses of AsA or DAsA to rainbow trouts for 6 weeks, no increase in plasma DAsA levels was observed while there was also no increase in blood glucose levels.

GSH is a well-known intracellular tripeptide that acts as a reducing agent and a free radical scavenger. It plays an important role in preventing oxidative damage in liver, endothelial tissue, and heart. ${ }^{153}$ Both AsA and GSH act as homeostatic systems; a positive correlation between AsA and GSH exists in some tissues. Martenson and Meister ${ }^{18)}$ showed that the depletion of GSH led to depletion of tissue AsA in newborn rats. Dabrowski et al. ${ }^{17)}$ reported that the GSH concentration in viscera of rainbow trout decreased significantly when the fish were fed with AsAdeficient diets. In the present study, however, no decrease in the GSH concentrations of the tissues was observed in rainbow trout fed with AsA-free diets for 6 weeks. Furthermore, no significant differences in AsA and DAsA concentrations in various tissues and blood were observed between AsA-supplemented and DAsAsupplemented groups. If GSH was the main reducing agent of DAsA, DAsA-supplemented groups would reduce GSH concentration more than AsA-supplemented groups. Basu et al. ${ }^{18)}$ postulated that the reduction of DAsA in human erythrocytes was coupled with the GSH-regenerating system. Recently, Choi and Rose ${ }^{18)}$ reported that DAsA reduction was catalyzed by a soluble enzyme that transferred hydrogen from NADPH to GSSG. Accordingly, such a system may be coupled to a greater extent with the reaction involving DAsA and GSH in rainbow trout resulting in little decrease in the GSH level. Further investigation is needed to elucidate the reduction mechanisms of DAsA in the fish body.

From the results obtained in this experiment, it is suggested that the DAsA present in fish feed is readily reduced to AsA in the fish body and can be effectively utilized by the rainbow trout as a vitamin $\mathrm{C}$ source.

\section{References}

1) Y, Kagawa: Biosynthesis and metabolism of L-ascorbic acid. in "Bitamingaku II" (ed. by Nippon Bitamin Gakkai), Tokyo Kagakudojin, Tokyo, 1980, pp. 578-584 (in Japanese).

2) C. M. Damron, M. M. Monier, and J. H. Roe: Metabolism of L-ascorbic acid, dehydro-L-ascorbic acid, and diketo-Lgulonic acid in the guinea pig. J. Biol. Chem., 195, 599-606 (1952).

3) P. G. Dayton, M. M. Snell, and J. M. Perel: Ascorbic and dehydroascorbic acids in guinea pigs and rats. $J$. Nutr., 88, 338-344 (1966).

4) E. D. Ritter, N. Cohen, and S. H. Rubin: Physiological avaliability of dehydro-L-ascorbic acid and palmitoyl-Lascorbic acid. Science, 113, 628-631 (1951).

5) M. Tsujimura, S. Watanabe, K. Michinaka, S. Tokuhisa, and A. Fujita: Metabolism of ascorbic acid and dehydroascorbic acid in man. Vitamins (Japan), 45, 136-147 (1972).

6) B. E. Clayton, R. R. McSwiney, and F. T. G. Pruntry: Metabolism of dehydroascorbic acid and the effect of adrenocorticotrophic hormone and cortisone. Biochem. J., 58, 542-552 (1954).

7) M. Otsuka, T. Kurata, and N. Arakawa: Antiscorbutic effect of dehydro-L-ascorbic acid in vitamin $\mathrm{C}$-deficient guinea pigs. J. Nutr: Sci. Vitaminol., 32, 183-190 (1986).

8) M. Tsujimura: Synthesis of dehydroascorbic acid. Jyoshi Eiyou Daigaku Kiyou, 1, 31-36 (1970).

9) M. Sato, T. Miyasaki, and R. Yoshinaka: Utilization of 
L-ascorbyl 2-phosphate in rainbow trout as a dietary vitamin C source. Nippon Suisan Gakkaishi, 57, 1923-1926 (1991).

10) S. Ikeda, M. Sato, and R. Kimura: Biochemical studies on $\mathbf{L}$ ascorbic acid in aquatic animals-I. An improved method for assessment. Nippon Suisan Gakkaishi, 29, 757-764 (1963).

11) M. Sato, Y. Hatano, and R. Yoshinaka: L-Ascorbyl 2 sulfate as a dietary vitamin $\mathrm{C}$ source for rainbow trout Oncorhynchus mykiss. Nippon Suisan Gakkaishi, 57, 717721 (1991).

12) B. M. Tolbert: Metabolism and function of ascorbic acid and its metabolites. Int. J. Vit. Nutr. Res. Suppl., 27, 121. 138 (1985).

13) J. W. Patterson: Course of diabetes and development of cataracts after injecting dehydroascorbic acid and related substances. Am. J. Physiol., 165, 61-65 (1951).

14) I. B. Chatterjee, A. K. Majumder, B. K. Nandi, and N. Subramanian: Synthesis and some major functions of vitamin $C$ in animals. Ann, N, Y, Acad Sci., 258, 24-47 (1975),
15) M. Tsan, E. H. Danis, P. J, Del Vecchio, and C. L. Rosano: Enhancement of intracellular glutathione protects endothelial celis against oxidative damage. Biochem. Biophys. Res. Commun., 127, 270-272 (1985).

16) J. Mortensson and A. Meister: Glutathione deficiency decreases tissue ascorbate levels in newborn rats: Ascorbate spares glutathione and protects. Proc. Natl. Acad. Sci. USA., 88, 4656-4660 (1991).

17) K. Dabrowski, N. El-Fiky, G. Köch, M. Frigg, and W, Wieser: Requirement and utilization of ascorbic acid and ascorbic sulfate in juvenile rainbow trout. Aquaculture, 91, 317-337 (1990).

18) S. Basu, S. Som, S. Deb, D. Muherjee, and I. B. Chatterjee: Dehydroascorbic acid reduction in human erythrocytes. Biochem. Biophys. Res. Commun, 90, 1335-1340 (1979).

17) J.-L. Choi and R. C. Rose: Regeneration of ascorbic acid by rat colon. Proc. Soc. Exp. Biol. Med., 190, 369-374 (1989) 